\title{
ISRAEL, HEZBOLLAH E O CONFLITO ASSIMÉTRICO
}

\author{
General Álvaro Pinheiro ${ }^{1}$
}

Os termos "Assimetria", "Conflito Assimétrico" e "Guerra Assimétrica" são de uso recente no linguajar estratégico militar. O conceito de "Conflito Assimétrico" surgiu pela primeira vez nas publicações conjuntas das Forças Armadas norte-americanas em 1995, sendo, a partir daí, difundido e desenvolvido. Não raro, entretanto, o uso indiscriminado do termo tem distorcido o seu conceito básico e gerado dicotomias no seu entendimento.

Fundamentalmente, o "Conflito Assimétrico" é a confrontação entre o "fraco" e o "bem mais forte". As situações em que um dos contendores, em presença, possui um poder de combate significativamente superior ao de seu(s) oponente(s), tem sido alvo dos estudos de conceituados formuladores do pensamento e da estratégia militar tais como Sun Tzu, Clausewitz e Beauffre. E as aplicações práticas de suas táticas, técnicas e procedimentos estão presentes na história militar desde que Aníbal evitou a invasão de Cartago pelos romanos, até os dias de hoje, nos recentes combates conduzidos no Afeganistão e no Iraque. A "Guerra Brasílica", desenvolvida no Nordeste brasileiro de 1624 a 1654, evento histórico de grande relevância na formação da nacionalidade brasileira, bem como a “Guerra do Vietnã", desenvolvida no Sudeste da Ásia , de 1963 a 1975, são magníficos exemplos da condução de "Conflitos Assimétricos".

A condução de uma campanha, baseada na "Assimetria", é uma opção adotada pelo oponente "bem mais fraco". Trata-se da única linha de ação deste oponente, no nível político-estratégico, que lhe possibilita a obtenção do sucesso na resolução da confrontação. E para materializar as ações a realizar, o planejamento da guerra nos seus três níveis básicos, estratégico, operacional e tático, é impositivamente fundamentado nos conceitos e fundamentos da "Guerra Irregular". Este tipo de confrontação bélica, que também pode ser identificado como "Guerra Não-convencional", impõe a seleção de um ambiente operacional que restrinja de forma significativa a utilização dos meios bélicos do oponente "bem mais forte", particularmente aqueles meios que possuem elevado nível científico-tecnológico. Os elementos básicos que caracterizam esta forma de combate são a tática/técnica de guerrilhas, a subversão, a sabotagem e, não raro, o terrorismo. A condicionante do tempo se faz de grande relevância, uma vez que a longa duração do conflito é inerente à condução da campanha, visando à consecução de seus objetivos pelas forças irregulares ou não-convencionais. Trata-se de uma guerra de desgaste em que o condicionante moral, materializado pela determinação das forças irregulares e o apoio da população civil não-combatente à causa em presença, ganham uma relevância significativa.

A decisão de combater um inimigo com poder de combate significativamente superior envolve riscos político-estratégicos significativos, avultando, além da longa duração do conflito, um grande desgaste em vidas humanas (combatentes ou não), e a escalada do conflito no campo regional ou mundial.

Osama bin Laden e a Al Qaeda, a partir dos trágicos eventos de 11 de setembro de 2001, inauguraram um tipo de "Assimetria" que se caracteriza pela participação direta de grupos radicais autônomos em confrontação contra Estados, empregando como sua principal estratégia, um novo terrorismo, de amplitude global, que tende a se tornar uma guerra sem limites.

\footnotetext{
${ }^{1}$ General da Brigada de Reserva, analista Militar especialista em Guerra irregular.
} 


\section{A Confrontação no Líbano}

As ações militares de retaliação, atualmente desencadeadas pelo Hezbollah e pelas Forças Armadas de Israel, no território do Líbano, estão dentro de um grande contexto que banha de sangue o Oriente Médio a décadas.

As ações ofensivas detonadoras do conflito conduzidas pelo Hezbollah, sob a orientação de seus patrocinadores, governos do Irã e da Síria, são, principalmente, a conseqüência de uma trégua concedida por Israel, desde que numa decisão unilateral abandonou o Líbano, em maio de 2000. Nesses seis anos, o Hezbollah pode reorganizar suas estruturas e seus recursos humanos e materiais, transformando-se numa força irregular muito bem equipada e adestratada. Hoje, diferentemente do passado, o Hezbollah tem seus três braços irregulares perfeitamente constituídos. O braço armado ostensivo, a força de guerrilha, apta, inclusive, a ações limitadas de conquista e manutenção de acidentes capitais no terreno; o braço clandestino, a força subterrânea, responsável pelas ações de subversão, sabotagem e de terrorismo seletivo e indiscriminado; e o seu braço logístico, a força de sustentação, com cadeias de suprimento muito bem estruturadas. Essa poderosa força irregular, inclusive, segundo dados do Mossad, estaria equipada com cerca de 13000 a 15 000 mísseis de curto e médio alcance. O líder do Hezbollah, Hassan Nasrallah, teve condições de planejar meticulosamente como atacar as comunidades israelenses localizadas ao Norte do País, junto à fronteira com o Líbano.

O Hezbollah, "Partido de Deus", não tem limites. Qualquer ação ofensiva que puder ser realizada, o será, limitada apenas pela sua própria capacitação e pelas condições que possibilitem o desencadeamento da ação num momento específico.

A decisão de Nasrallah de desencadear um ataque de saturação com mísseis no Norte de Israel, bem como seqüestrar dois soldados reservistas israelenses, em 12 de julho, foi tomada tendo como referência a ação perpetrada pelo Hamas na fronteira Israel-Gaza, seqüestrando o Cabo do Exército israelense Gilad Shalit. Segundo Hassan Nasrallah, a intenção do Hezbollah seria negociar a liberação dos militares israelenses em troca de Samir Kuntar, um perigoso terrorista libanês, a serviço do Hezbollah, bem como de outros terroristas mantidos presos pelas forças de segurança de Israel.

Segundo fontes da inteligência israelense, Hassan Nasrallah teria, inclusive, a intenção de assumir as negociações em nome do Hamas, incrementando, sobremaneira, a participação do Hezbollah na questão palestina, assumindo uma posição mais destacada do que a do próprio Hamas.

\section{A Resposta Israelense}

Não apenas o Irã , a Síria e o próprio Hezbollah foram surpreendidos com a intensidade da violência da resposta israelense aos ataques de mísseis e aos seqüestros. O mundo, de uma maneira geral, o foi.

Fica muito claro que as autoridades israelenses entenderam que a ação desencadeada pelo Hezbollah tinha um caráter estratégico de significativa ameaça, não só de ameaça ao povo israelense, como à própria sobrevivência de Israel como Estado livre, soberano e independente; razão pela qual a retaliação, necessariamente, deveria ter um relevante peso específico dissuasório. As forças de segurança de Israel consideraram que mais do que uma mera resposta a uma organização terrorista, como o Hamas, na faixa de Gaza, tratava-se de destruir uma força irregular disciplinada, adestrada, muito bem equipada, com um alto padrão de capacitação operacional e um decisivo apoio do Irã e da Síria.

\section{O Papel do Irã}

Asharq Al-Awsat, um alto funcionário do governo iraniano, declarou em Londres, em 11 de maio de 2006, numa reunião com diplomatas de países europeus, que o Hezbollah era 
um dos pilares básicos da estratégia de segurança do Irã, integrando sua primeira linha de defesa contra Israel. E que, assim, de forma alguma o governo iraniano admitiria a possibilidade de desarmá-lo e desmobilizá-lo, conforme exigido pela Resolução 1559 do Conselho de Segurança da ONU. Walid Jumblatt, líder druso libanês, ratificou que "a guerra não é mais do Líbano. É uma guerra do Irã. E a mensagem aos Estados Unidos é que quaisquer ações desencadeadas visando ao desmonte do programa nuclear iraniano teria como resposta, significativas agressões contra Israel."

O Hezbollah não é, definitivamente, um ator independente. A Guarda Revolucionária Iraniana, força terrestre de elite, tem a responsabilidade de apoiar o Hezbollah em armamento, munição, adestramento, suporte financeiro e comando e controle de nível estratégico. A maior parte do arsenal terrorista do Hezbollah , particularmente os mísseis de curto e de médio alcance, incluindo o Zatzal, que pode atingir Tel Aviv, a 150 quilômetros da fronteira norte de Israel, são fabricados no Irã e exportados via Aeroporto Internacional de Damasco, na Síria. Daí, o material bélico é transportado em comboios motorizados ao Hezbollah, no Líbano.

Segundo a inteligência israelense, oficiais da Guarda Revolucionária estão no terreno, no Líbano, participando decisivamente da supervisão de ações terroristas e do lançamento de mísseis contra o território de Israel. A 14 de julho, o Hezbollah lançou uma cópia iraniana do míssil chinês C-802 Kowthar contra um navio da Marinha israelense, matando 4 membros de sua tripulação. Esses mísseis fazem parte do arsenal iraniano, já há quatro anos.

Os foguetes da primeira barragem do ataque contra a cidade israelense de Haifa, em 16 de julho, eram de fabricação síria.

\section{Condicionantes Estratégicas do Conflito}

Basicamente, são quatro as grandes condicionantes estratégicas do presente conflito.

A primeira é o incondicional apoio dos Estados Unidos a Israel. Todavia, Washington se preocupa em manter o conflito, o mais limitado possível, evitando uma escalada. Há que se ter em mente que as Forças Armadas israelenses estão em plenas condições de atacar diretamente alvos estratégicos no Irã e na Síria. Porém, as conseqüências de uma iniciativa dessa natureza poderiam contribuir, decisivamente, para uma desestabilização de toda a região, inclusive com uma mudança de postura dos aliados norte-americanos no Oriente Médio, particularmente, Egito, Arábia Saudita e Jordânia.

A segunda condicionante é a constatação de que a ação de retaliação militar israelense, muito mais do que punitiva, é essencialmente estratégica. A Força Aérea de Israel está destruindo as principais vias de acesso por onde se realiza o transporte do apoio logístico ao Hezbollah, a partir da Síria e do Irã, via Aeroporto Internacional de Beirute, todos os portos marítimos do Líbano, e a auto-estrada que une Beirute a Damasco. As vias através do Vale do Bekaa, que, em determinados momentos, foram utilizadas pela Síria, também estão sendo interditadas. Bombardeando o ponto forte do Hezbollah, identificado como Daheyh, nos subúrbios ao Sul de Beirute, Israel pretende isolá-lo de forças irregulares posicionadas mais ao Sul.

Nesse contexto, Israel, além de ter desalojado o Hezbollah de suas privilegiadas posições no Sul do Líbano, junto à fronteira Líbano - Israel, o está isolando do Irã e da Síria, bem como do resto do Líbano. Esta manobra de isolamento é a primeira fase da completa neutralização da ameaça. A segunda fase será o desarmamento do Hezbollah, dando cumprimento à Resolução 1559 do Conselho de Segurança da ONU, que deverá ser efetuado, conforme as atuais gestões da comunidade internacional, a partir do estabelecimento de uma força de paz multinacional. 
A terceira condicionante é a constatação de que, no momento, mais do que nunca, o Hezbollah se constitui num apêndice da Guarda Revolucionária Iraniana. As autoridades israelenses entendem que as reais razões do desencadeamento das ações do Hezbollah pelo Irã, estão consoantes a um contexto que visa o objetivo estratégico de impedir quaisquer pressões sobre o desmonte do programa nuclear iraniano. E, sem dúvida alguma, a neutralização da capacidade militar do Hezbollah é fundamental para que a comunidade internacional possa continuar a pressionar sobre o referido programa.

A quarta condicionante está ligada à assertiva norte-americana e israelense de que o Líbano só será um estado livre e democrático, quando o Hezbollah estiver completamente neutralizado. Este entendimento seria comum aos demais países da região, cujos governos discordam das ações terroristas desestabilizadoras, desencadeadas pelo Hezbollah. Por outro lado, as ações de retaliação israelense deixam claro ao Presidente Bashar Assad (que no ano passado teve que retirar os grandes efetivos do Exército Sírio do Líbano, mediante forte pressão da comunidade internacional) de que qualquer ação militar síria no Líbano será prontamente destruída.

\section{A Frente Diplomática}

A chamada comunidade internacional está ciente de que o Hezbollah sempre foi (e continua sendo) uma organização terrorista, cujos objetivos, via de regra, inclusive no presente conflito, são comunidades civis não combatentes. A própria América do Sul já testemunhou dois sangrentos atentados desencadeados nos anos de 1992 e 1994 (respectivamente contra a Embaixada de Israel e contra a Associação Mutual Israelense Argentina) na cidade de Buenos Aires, com um grande número de baixas entre inocentes civis argentinos.

Todavia, percebe-se também uma rejeição da comunidade internacional à intensidade da violência desenvolvida pelas forças de Israel. Sobretudo, porque, infelizmente, inúmeros danos colaterais que redundam em significativo número de baixas entre civis libaneses estão sendo registrados.

Os governos norte-americano e israelense e uma parte significativa de países integrantes da Comunidade Européia de Nações estão cientes de que Israel necessita concluir a retaliação militar de forma plena. E tal fato só ocorrerá caso seja vencida a batalha na frente diplomática.

Não resta dúvida que o pleno desmonte da capacitação militar do Hezbollah é algo de interesse de todo o mundo civilizado e um passo decisivo para que se possa pensar na consecução de um efetivo processo de paz para o Oriente Médio.

\section{Bibliografia}

MajGen (Ret) Yaakov Amidror and Dan Diker. "Fighting Hizbollah", Jerusalem Center for Public Affairs.

Middle East Research Media Institute (MERMI)

Anton La Guardia , "Israel Fights West's Cause Against Radical Islam", Daily Telegraph (UK), July 17, 2006. 